\title{
Observed and predicted characteristics of equatorial F1 layer during solar minimum
}

\author{
C.-C. Lee
}

General Education Center, Chien Hsin University of Science and Technology, No.229, Jianxing Rd., Zhongli City, Taoyuan County 320, Taiwan

Correspondence to: C.-C. Lee (cclee@uch.edu.tw)

Received: 25 November 2013 - Revised: 8 April 2014 - Accepted: 15 April 2014 - Published: 28 May 2014

\begin{abstract}
This study aims to assess the predictability of IRI-2012 on the equatorial F1 layer during solar minimum. The observed characteristics of F1 layer by the Jicamarca digisonde are compared with the model outputs. The results show that the time range for F1-layer appearance of observation is longer than that of IRI-2012, by at least $1 \mathrm{~h}$ in the early morning and later afternoon. In IRI-2012, there are three options for the occurrence probability of F1 layer: IRI95, Scotto-97 no L, and Scotto-97 with L options. The first option predicts the probability well, but the last two underestimate the probability. The peak density of $\mathrm{F} 1$ layer $(\mathrm{NmF} 1)$ of observation is very close to that of IRI-2012. For the F1 peak height $(h m \mathrm{~F} 1)$, the modeled values are smaller than the observed ones. The observed seasonal variation of $h m \mathrm{~F} 1$ is not found in the modeled results. Nevertheless, the observed diurnal variation of $h m \mathrm{~F} 1$ is similar to the modeled results with the B0 choices of Bil-2000 and ABT-2009. Regarding the shape parameter, the values of D1 (the shape parameter of F1 layer in observation) are much greater than the values of $\mathrm{C} 1$ (the shape parameter of F1 layer in IRI-2012). The D1 values are 3-6 times the $\mathrm{C} 1$ values. The diurnal variation of $\mathrm{D} 1$ is similar to that of $\mathrm{C} 1$, but the seasonal variation of $\mathrm{D} 1$ is not.
\end{abstract}

Keywords. Ionosphere (equatorial ionosphere; modeling and forecasting)

\section{Introduction}

In 1969, the Committee on Space Research (COSPAR) and the International Union of Radio Science (URSI) initiated the International Reference Ionosphere (IRI). IRI is an empirical standard model of the ionosphere, based on all worldwide available data from ground-based and satellite observations (e.g., Bilitza, 1990). Since the late 1960s, IRI has been continuously improved with newer data and better model techniques. These processes have resulted in several major milestone editions of the model, including the IRI-78 (Rawer et al., 1978), IRI-85 (Bilitza, 1986), IRI-1990 (Bilitza, 1990), IRI-2001 (Bilitza, 2001), and IRI-2007 (Bilitza and Reinisch, 2008). The latest edition of IRI model is the IRI-2012 (http: //iri.gsfc.nasa.gov/).

In order to evaluate the predictability of IRI, the modeled outputs are usually compared with measured ionospheric variables. In the equatorial ionosphere, there were many studies applying ionosonde and digisonde data to validate the F2-layer parameters of IRI model (Adeniyi and Adimula, 1995; Adeniyi and Radicella, 1998a, b; Reinisch and Huang, 1998; Adeniyi et al., 2003; Obrou et al., 2003; Abdu et al., 2004; Batista and Abdu, 2004; Lee and Reinisch, 2006, 2012; Lee et al., 2008). The F2-layer parameters are the F2-layer peak electron density $(N m \mathrm{~F} 2)$, its height $(h m \mathrm{~F} 2)$, and the bottom-side profile parameters (B0 and $\mathrm{B} 1)$. In these previous studies, the comparisons between the observed and predicted results were conducted in different longitudinal sectors and in different solar epochs. Unlike the study of F2 layer, however, there is less work on the equatorial F1 layer than on the equatorial F2 layer. Adeniyi (1996) might be the only study, which compared the observed F1layer peak density $(N m \mathrm{~F} 1)$ and height $(h m \mathrm{~F} 1)$ with the IRI modeled outputs at Ibadan, Nigeria $\left(7.4^{\circ} \mathrm{N}, 3.9^{\circ} \mathrm{E}\right.$; dip latitude: $6.3^{\circ} \mathrm{S}$ ).

As mentioned above, the studies for the equatorial F1 layer are very few. Furthermore, it is important that IRI provides well-established ionospheric profiles for the ionospheric scientists. Accordingly, a validation for all F1-layer 

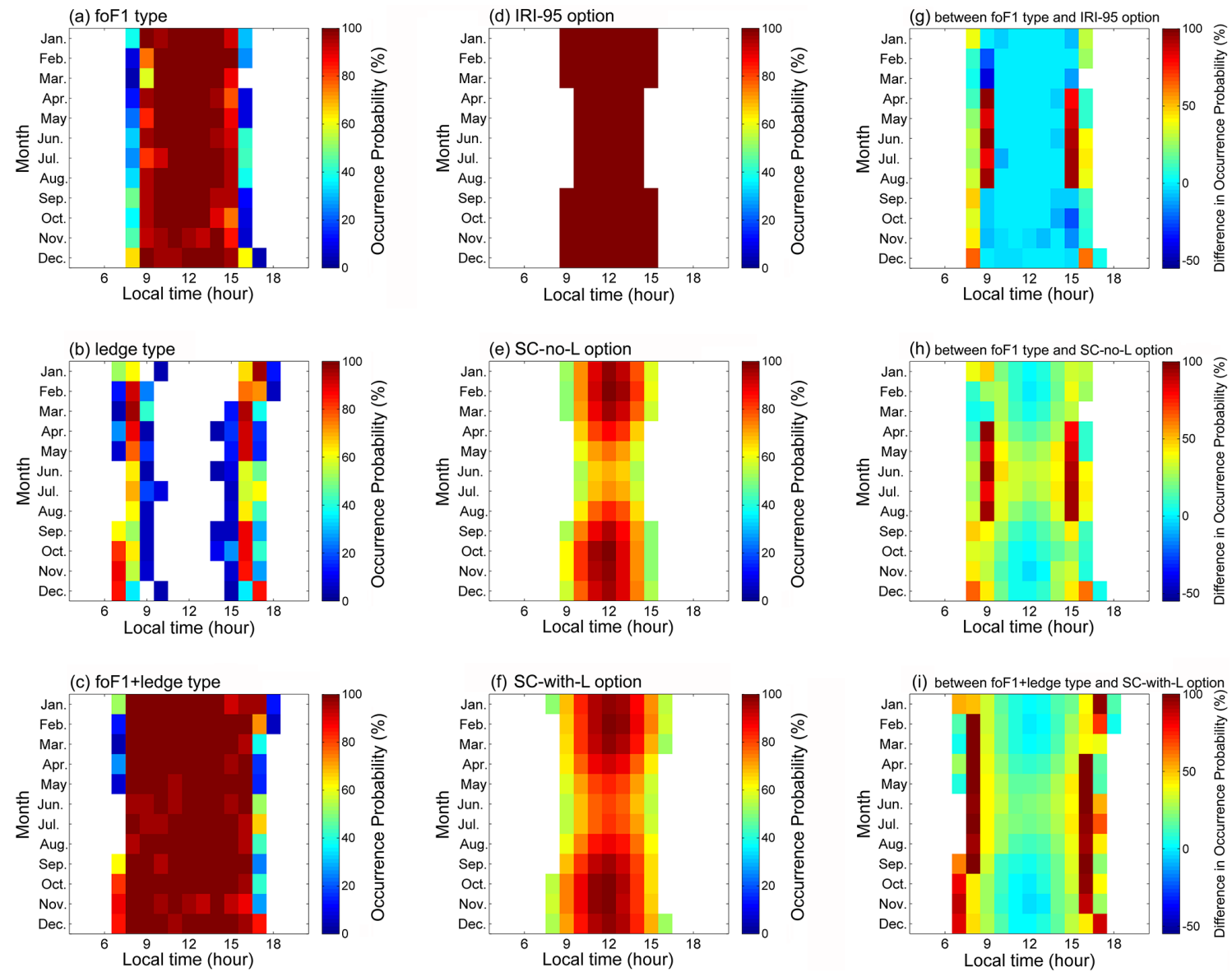

Figure 1. The F1-layer occurrence probabilities for the (a) $f_{o} \mathrm{~F} 1$, (b) ledge, and (c) $f_{o} \mathrm{~F} 1+$ ledge types of the Jicamarca digisonde, and for the (d) IRI-95, (e) SC-no-L, and (f) SC-with-L options of IRI-2012 during January-December 1996. The differences in occurrence probabilities (g) between $f o F 1$ type and IRI-95 option, (h) between $f o F 1$ type and SC-no-L option, and (i) between $f o F 1+$ ledge type and SC-with-L option are presented.

characteristics of IRI is required. The aim of this paper is to investigate how well the IRI-2012 predicts the F1-layer characteristics at Jicamarca, Peru $\left(12^{\circ} \mathrm{S}, 76.9^{\circ} \mathrm{W}\right.$; dip latitude: $1.0^{\circ} \mathrm{N}$ ), during solar minimum. The occurrence probability, $N m \mathrm{~F} 1, h m \mathrm{~F} 1$, and profile shape parameter (D1) of $\mathrm{F} 1$ layer obtained from the observed ionogram are compared with those modeled by IRI-2012. The data period is between January and December 1996. It is noted that the solar cycle 23 started in May 1996 with the monthly smoothed sunspot number of 8.0 .

\section{Data}

In this study, the ionograms were observed by the Jicamarca digisonde $\left(12^{\circ} \mathrm{S}, 76.9^{\circ} \mathrm{W}\right)$, located near the geomagnetic equator. The recorded ionograms in 1996 provide the hourly data of F1-layer characteristics during solar minimum. It is noted that the Jicamarca ionograms were downloaded from the Digital Ionogram DataBase (DIDBase), and the ionograms were manually edited with the SAO Explorer software package (http://ulcar.uml.edu/digisonde.html). The occurrence probability is the number of F1-layer events in a certain hour divided by the number of observed ionograms in this hour for a month. $N m \mathrm{~F} 1$ is calculated from the critical plasma frequency, $f o \mathrm{~F} 1$, of the $\mathrm{F} 1$ layer by $N m \mathrm{~F} 1\left(\mathrm{el} \mathrm{m}^{-3}\right)=$ $1.24 \times 10^{10} \cdot(f o \mathrm{~F} 1 / \mathrm{MHz})^{2} . h m \mathrm{~F} 1$ and $\mathrm{D} 1$ are derived using the true height inversion algorithm NHPC (ftp://umlcar.uml. edu/SoftwareUtilities/NHPC/) (Reinisch and Huang, 2000; Huang and Reinisch, 2001) imbedded in the SAO Explorer software package (Reinisch, 1996; Huang and Reinisch, 2001). D1, a shape parameter, is used to describe the shape of F1-layer profile, obtained from the digisonde observation (Reinisch and Huang, 2000). Moreover, the F1 layer is categorized into two types: (1) foF1 and (2) ledge types (Piggott and Rawer, 1972; Adeniyi and Radicella, 1997). The foF1 type is defined when a well-developed cusp is formed between the E and F2 layers, or a distinct transition point is formed between the end of the F1 layer and the beginning of the F2 layer. For the other type, the F1 layer is not 

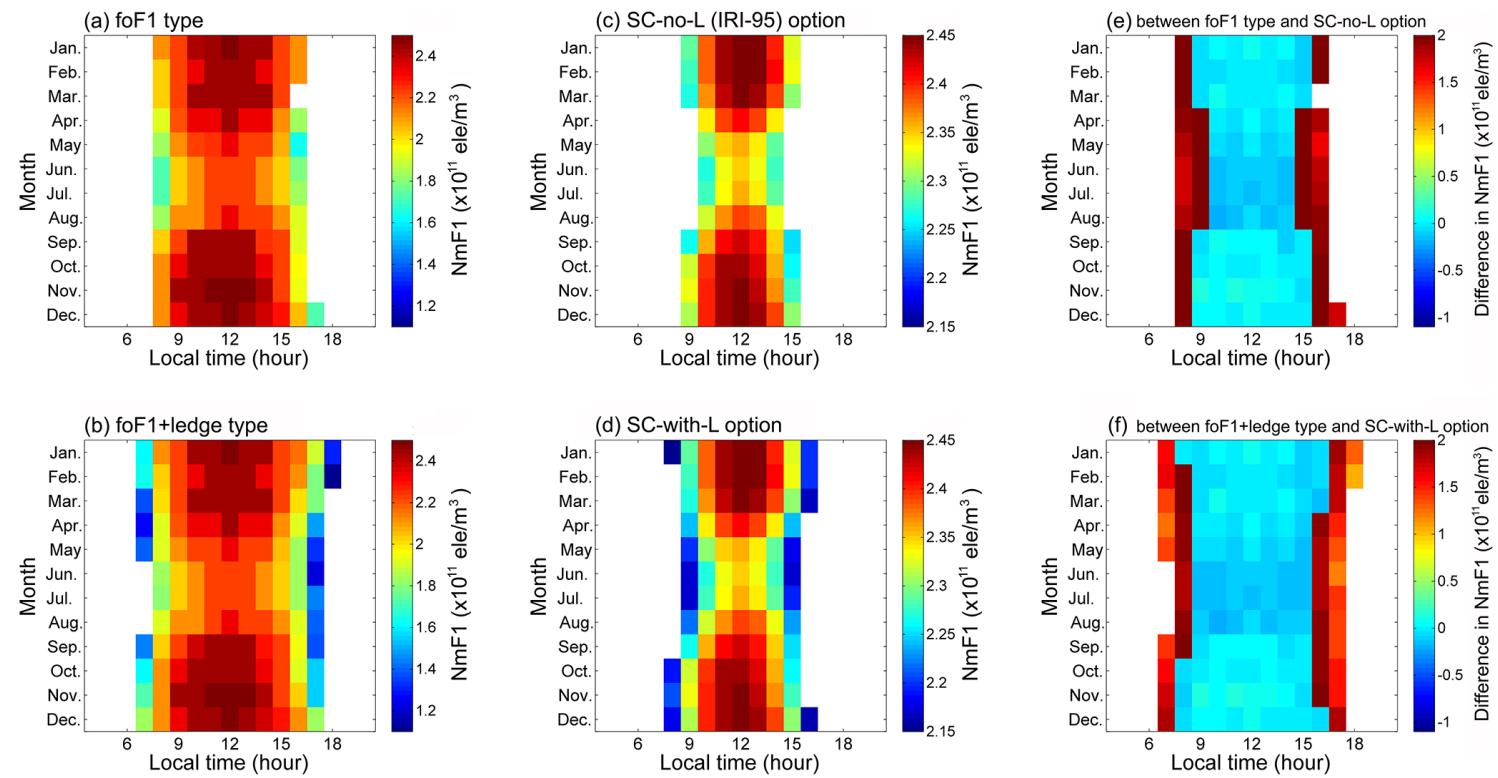

Figure 2. The monthly median $N m \mathrm{~F} 1$ values for the (a) $f_{o} \mathrm{~F} 1$ and (b) $f_{o} \mathrm{~F} 1+$ ledge types of the Jicamarca digisonde, and for (c) SC-no-L and (d) SC-with-L options of IRI-2012 during January-December 1996. The differences in NmF1 (e) between foF1 type and SC-no-L option, and (f) between $f o \mathrm{~F} 1+$ ledge type and SC-with-L option are displayed.

fully developed, but a ledge (L-condition) is observed below the F2 layer. To eliminate the effects of geomagnetic disturbances, the data only under geomagnetic quiet conditions $(\Sigma \mathrm{Kp} \leq 24)$ are included in the study. It is noted that the geomagnetic quiet condition is defined as $\Sigma \mathrm{Kp} \leq 24$, where $\Sigma \mathrm{Kp}$ is the sum of the eight 3-hourly Kp indices for a day.

In addition to the observed data, the values of occurrence probability, $N m \mathrm{~F} 1, h m \mathrm{~F} 1$, and $\mathrm{C} 1$ modeled by the IRI-2012 are applied in this work. $\mathrm{C} 1$ is a shape parameter describing the shape of F1-layer profile of IRI-2012 (Bilitza et al., 1990). Because both C1 and D1 are used to describe the shape of F1-layer profile, C1 of IRI-2012 is compared with D1 of observation. The F1-layer occurrence probability of IRI-2012 has three options: (1) IRI-95 (DuCharme et al., 1973), (2) Scotto-97 no L (SC-no-L), and (3) Scotto-97 with L (SC-with-L) (Scotto et al., 1997). It is noted that "L" in the labels of the last two options represents the L-condition (the ledge type of F1 layer) (Scotto et al., 1997). For the IRI-95 option, an F1 layer ( $f o \mathrm{~F} 1$ type) is only assumed to exist when the solar zenith angle $(\chi)$ is smaller than or equal to $\chi_{\mathrm{m}} \cdot \chi_{\mathrm{m}}$ is the maximum solar zenith angle, which is calculated from a function of geomagnetic latitude $(\lambda)$ and 12-month smoothed sunspot number $\left(R_{12}\right)$. The detailed definition of $\chi_{\mathrm{m}}$ can be found in DuCharme et al. (1973). The occurrence probability for this option is $0 \%(100 \%)$, as $\chi>\chi_{\mathrm{m}}\left(\chi \leq \chi_{\mathrm{m}}\right)$. Regarding the other two options, the occurrence probabilities are calculated from a function of $\chi, \lambda$, and $R_{12}$. The definition of the probability function for the SC-no-L and SCwith-L options is described by Scotto et al. (1997). The SCno-L option gives the occurrence probability of foF1 type, while the SC-with-L option provides the occurrence probability of $f o \mathrm{~F} 1+$ ledge type, which means that both $f o \mathrm{~F} 1$ and ledge types are taken together. For $N m \mathrm{~F} 1$, only one option is built in the model (DuCharme et al., 1973). Regarding $h m \mathrm{~F} 1$, the value will be affected by the choice of B0 (Bilitza, 1990). Therefore, all three choices of B0 - (1) Gul-1987 (Gulyaeva, 1987), (2) Bil-2000 (Bilitza et al., 2000), and (3) ABT-2009 (Altadill et al., 2008, 2009) - are applied to model $h m \mathrm{~F} 1$. Based on the results of Reinisch and Huang (2000), since IRI-2001, the $\mathrm{C} 1$ value has been 2.5 times that of the earlier edition. Furthermore, the observed Ap and F10.7 indices are inputted in the IRI modeling to consider the month-to-month variability. Also, the hourly data of occurrence probability, $N m \mathrm{~F} 1, h m \mathrm{~F} 1$, and $\mathrm{C} 1$ under geomagnetic quiet conditions are used in this study.

\section{Results and discussions}

\subsection{Occurrence probability}

Figure 1a-c show that the occurrence probabilities of F1 layer, obtained from the Jicamarca ionograms, for the (a) $f_{o} \mathrm{~F} 1$, (b) ledge, and (c) $f o \mathrm{~F} 1+$ ledge types during JanuaryDecember 1996. For the $f o F 1$ type (Fig. 1a), the F1 layer appears from 08:00 to 16:00 LT. The occurrence probability does not vary with the seasons. The occurrences are almost $100 \%$ during 10:00-14:00 LT, and exceed $80 \%$ at 09:00 and 15:00 LT. This demonstrates that the F1 layer of $f o \mathrm{~F} 1$ type certainly appears, when $\chi$ is smaller than $35^{\circ}$. In Fig. 1b, the ledge type exists generally at 07:00-09:00 LT and 
15:00-17:00 LT. The seasonal variation is also not found in the ledge type. In Fig. 1c, it is found that the appearance begins at 07:00 and ends at 17:00 LT, when the foF1 and ledge types are taken together. The occurrences are almost $100 \%$ between 08:00 and 16:00 LT. This indicates that the F1 layer of $f o \mathrm{~F} 1+$ ledge type certainly appears, as $\chi<65^{\circ}$. For the foF1 type, the occurrence probabilities in this study are similar to the results at low solar activity in Adeniyi (1996) and Adeniyi and Radicella (1997). Adeniyi (1996) and Adeniyi and Radicella (1997) investigated the equatorial F1 layer at Ibadan, Nigeria $\left(7.4^{\circ} \mathrm{N}, 3.9^{\circ} \mathrm{E}\right.$; dip latitude: $\left.6.3^{\circ} \mathrm{S}\right)$, and Ouagadougou, Burkina Faso $\left(12.4^{\circ} \mathrm{N}, 1.8^{\circ} \mathrm{W}\right.$; dip latitude: $5.9^{\circ} \mathrm{N}$ ), respectively. For the ledge type, Adeniyi and Radicella (1997) also reported that, at low solar activity, this type of F1 layer generally appears in the early morning and late afternoon. This result reveals that a ledge-like profile occurs just at the bottom of F2 layer, when an F1 layer starts to be formed in the early morning. And, before the layer vanishes, the $f_{o} \mathrm{~F} 1$-type $\mathrm{F} 1$ layer transforms into the ledge type in the late afternoon.

The occurrence probabilities of F1 layer predicted by IRI2012 are displayed in Fig. 1d-f. The results for the options of IRI-95, SC-no-L, and SC-with-L are presented in Fig. 1d, e, and f, respectively. In Fig. 1d, the occurrence probabilities are $100 \%$. The appearance is during 09:00-15:00 LT for January-March and September-December, and during 10:00-14:00 LT for April-August. For the SC-no-L and SCwith-L options, the occurrence probability will be outputted by IRI-2012, when its value is greater than or equal to $50 \%$. In Fig. 1e, the time ranges of appearance for the SC-noL option are the same as those for the IRI-95 option. The occurrence probability has a diurnal variation with a daily maximum value at 12:00 LT. Moreover, the occurrence probabilities are larger in the summer and equinoctial months but smaller in the winter months. In Fig. 1f, it is found that the diurnal and seasonal variations for the SC-with-L option are similar to those for the SC-no-L option. Nevertheless, the occurrence probability and time range of appearance for the SC-with-L option are slightly larger than those for the SCno-L option.

Figure $1 \mathrm{~g}-\mathrm{i}$ present the differences in occurrence probabilities between observation and model. In Fig. 1g, the occurrence probabilities of IRI-95 option are compared with those of observation (foF1 type). It is found that the IRI-95 prediction is close to the observation during 10:00-14:00 LT. The positive differences exist at 08:00-09:00 LT and 15:0016:00 LT, because the time range of appearance is not predicted well by the IRI-95 option. Figure $1 \mathrm{~h}$ shows the comparison result between observation ( $f o \mathrm{~F} 1$ type) and SC-noL option, while Fig. 1i displays the comparison result between observation ( $f o \mathrm{~F} 1+$ ledge type) and SC-with-L option. In Fig. $1 \mathrm{~h}$ and $1 \mathrm{i}$, it is found that the time ranges of appearance of the two options are shorter than those of observation, too. These results suggest that the time range of appearance predicted by IRI-2012 should be extended by at least $1 \mathrm{~h}$
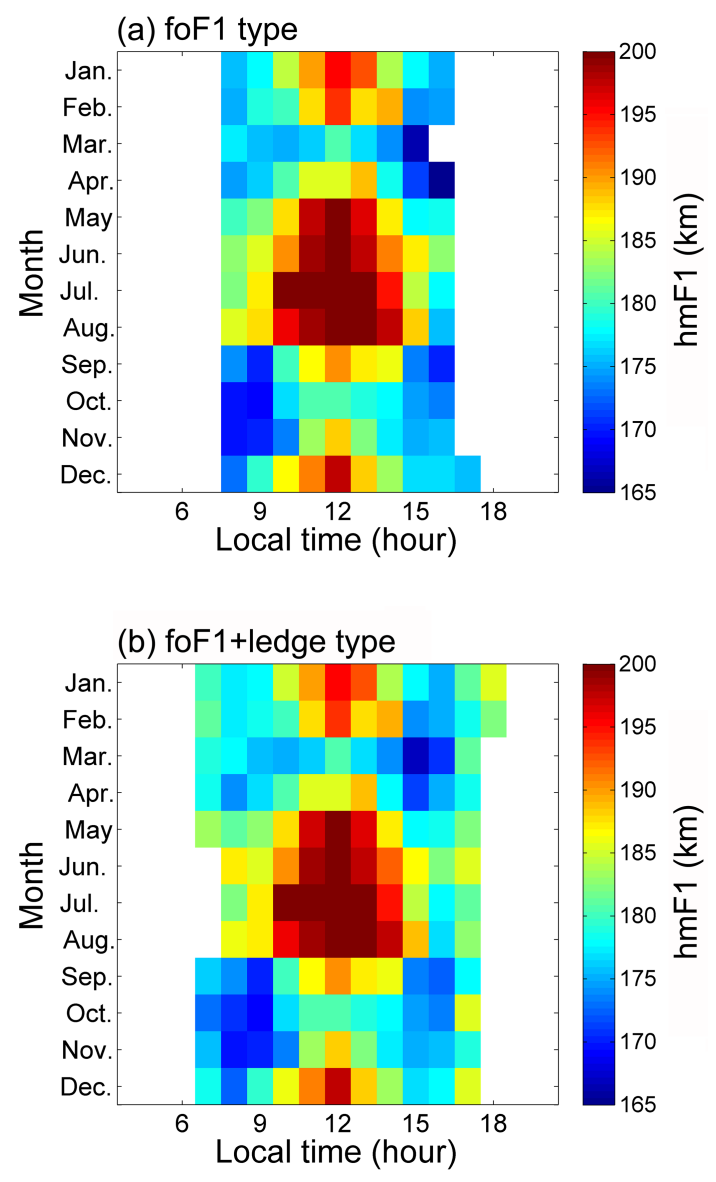

Figure 3. The monthly median $h m \mathrm{~F} 1$ values for the (a) $f o \mathrm{~F} 1$ and (b) $f o \mathrm{~F} 1+$ ledge types of the Jicamarca digisonde during JanuaryDecember 1996.

in the early morning and late afternoon. Furthermore, both SC-no-L and SC-with-L options significantly underestimate the occurrence probabilities, except during 11:00-13:00 LT of January-March and September-December. These significant differences are mainly because the seasonal variation in occurrence probabilities does not exist in the Jicamarca observation. These results demonstrate that the SC-no-L and SC-with-L options (Scotto et al., 1997) do not predict the occurrence probability of F1 layer well.

\subsection{Peak density}

The monthly median values of $N m \mathrm{~F} 1$, observed by the $\mathrm{Ji}$ camarca digisonde, for January-December of 1996 are displayed in Fig. 2a-b. In Fig. 2a (foF1 type), there is a diurnal variation in $N m \mathrm{~F} 1$. The $N m \mathrm{~F} 1$ values increase from 08:00 LT, have a maximum at 12:00 LT, and then decrease. A seasonal variation exists in $N m \mathrm{~F} 1$, which has the greater values in the summer and equinoctial months and the smaller values in the winter months. These kinds of diurnal and seasonal variations are also found in the $f o \mathrm{~F} 1+$ ledge type (Fig. 2b). These variations suggest that the $N m \mathrm{~F} 1$ values are dependent on 
(a) SC-no-L (IRI-95) option

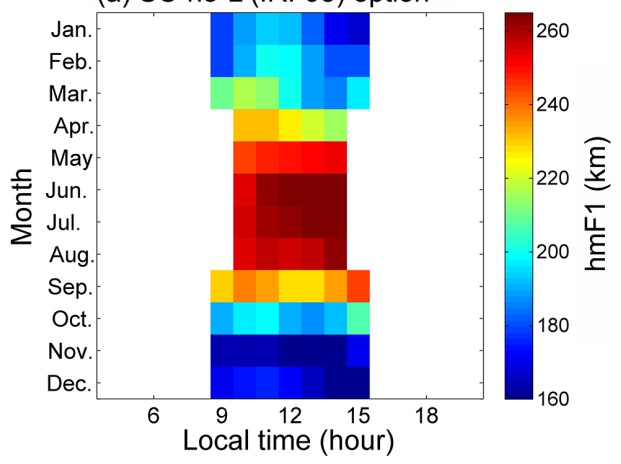

(b) SC-with-L option

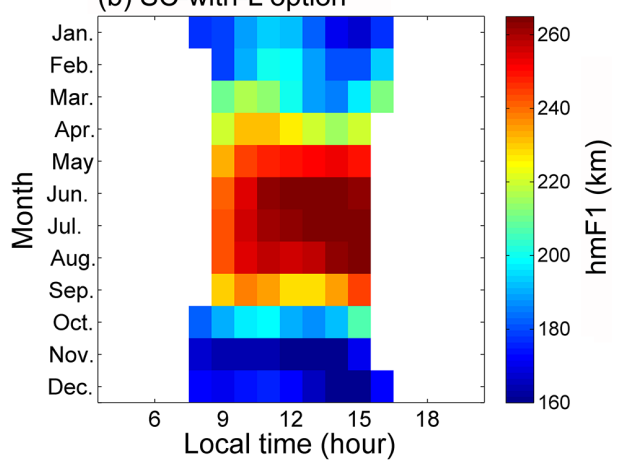

(c) between foF1 type and SC-no-L option

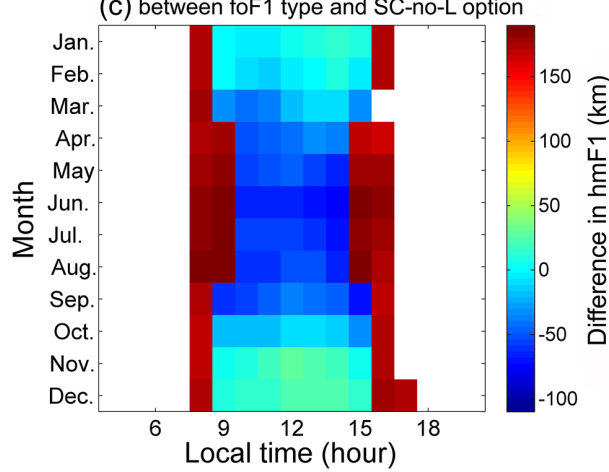

(d) between foF1+ledge type and SC-with-L option

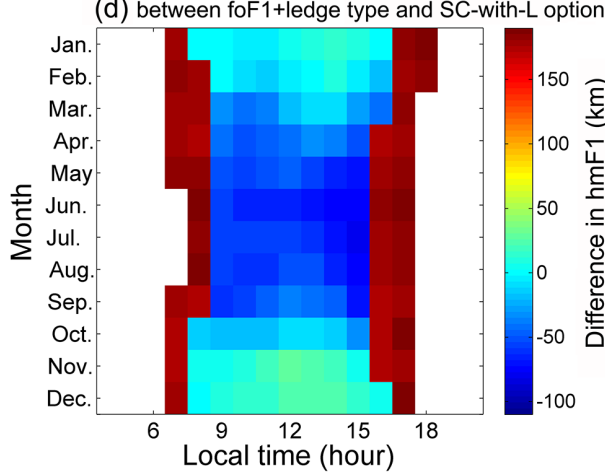

Figure 4. The monthly median $h m \mathrm{~F} 1$ values for (a) SC-no-L and (b) SC-with-L options, modeled by IRI-2012 with the B0 choice of Gul1987, during January-December 1996. The differences in $h m \mathrm{~F} 1$ (c) between $f o F 1$ type and SC-no-L option, and (d) between $f o F 1+l e d g e$ type and SC-with-L option are displayed.

$\chi$. Here, the correlation coefficient between $\log (\mathrm{NmF} 1)$ and $\log [\cos (\chi)]$ for each month is calculated. The correlation coefficient is estimated to be about 0.98 for all 12 months. This further suggests that $N m \mathrm{~F} 1$ can be represented by the relation of $N m \mathrm{~F} 1=a \cdot \cos ^{n}(\chi)$. The values of $a$ and $n$ are derived to be $2.50 \times 10^{11} \mathrm{ele}^{-3}$ and 0.33 , respectively. The $n$ of 0.33 indicates that the F1 layer is not an idealized Chapman layer, whose $n$ is 0.5 (e.g., Rishbeth and Garriott, 1969). Moreover, according to Rishbeth and Garriott (1969), $N m \mathrm{~F} 1$ would vary slowly with $\chi$ compared to the peak density of idealized Chapman layer, because the linear loss rate decreases with an increasing height. The values of $a$ and $n$ are close to those in Adeniyi and Radicella (1997), in which $a$ and $n$ were found to be $2.75 \times 10^{11} \mathrm{ele} \mathrm{m}^{-3}$ and 0.34 . However, there is no seasonal variation in $N m \mathrm{~F} 1$ in Adeniyi (1996) and Adeniyi and Radicella (1997).

Figure $2 \mathrm{c}-\mathrm{d}$ show the monthly median values of $N m \mathrm{~F} 1$, provided by IRI-2012, during January-December 1996. Because the $N m \mathrm{~F} 1$ variation of IRI-95 option is the same as that of SC-no-L option, the results of only SC-no-L (Fig. 2c) and SC-with-L (Fig. 2d) options are presented. For both options, the diurnal and seasonal variations appear in $N m \mathrm{~F} 1$. And these variations generally follow a solar zenith angle variation. The correlation coefficient between $\log (\mathrm{NmF} 1)$ and $\log [\cos (\chi)]$ is also calculated and the value is 1 . It is expected that coefficient is 1, because IRI-2012 applies the relation of $N m \mathrm{~F} 1=a \cdot \cos ^{n}(\chi)$ to predict $N m \mathrm{~F} 1$. Moreover, the values of $a$ and $n$ are derived to be $2.45 \times 10^{11} \mathrm{ele} \mathrm{m}^{-3}$ and 0.20 , respectively.

In Fig. 2e-f, the differences in $N m \mathrm{~F} 1$ between observation and IRI-2012 are calculated. The apparent differences in Fig. 2e are located at 08:00-09:00 LT and 15:00-16:00 LT. In Fig. 2f, the apparent differences exist at 07:00-08:00 LT and 16:00-17:00 LT. These differences are primarily caused by the shorter time ranges of appearance of IRI-2012. Except the apparent differences, IRI-2012 provides a good prediction of $N m \mathrm{~F} 1$, because both observed and modeled $N m \mathrm{~F} 1$ have the same dependence on $\chi$. Nevertheless, it is necessary to notice that $a$ for IRI-2012 is slightly smaller than for observation, while $n$ for IRI-2012 is greater than for observation.

\subsection{Peak height}

Figure 3 shows the monthly median values of $h m \mathrm{~F} 1$ for observation during January-December 1996. For the foF1 type (Fig. 3a), the values of $h m \mathrm{~F} 1$ have a diurnal variation. $h m \mathrm{~F} 1$ generally starts to rise at 08:00 LT, has the highest value at 12:00 LT, and then descends. This kind of diurnal variation indicates that $h m \mathrm{~F} 1$ is negatively correlated 
(a) SC-no-L (IRI-95) option

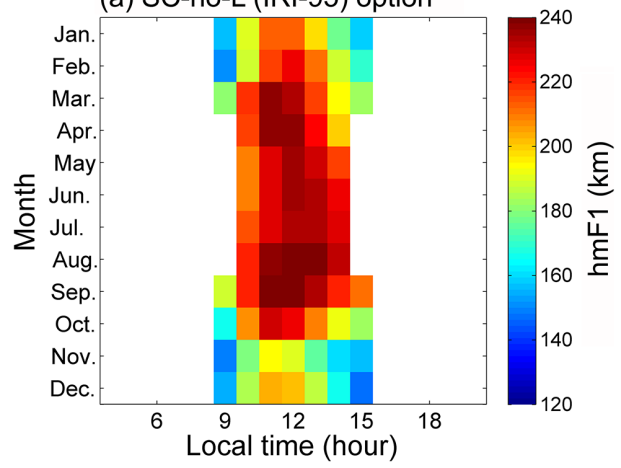

(b) SC-with-L option

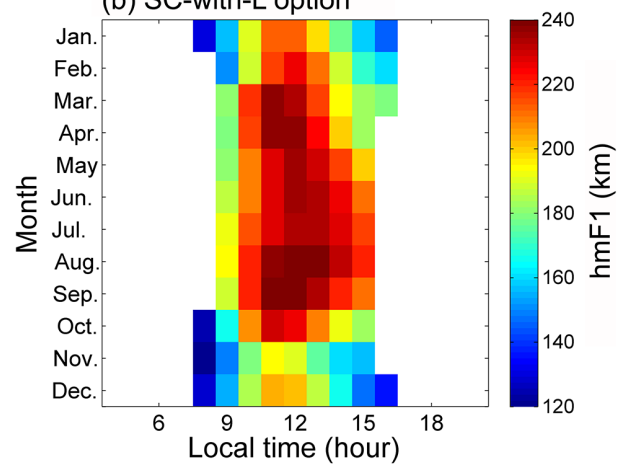

(c) between foF1 type and SC-no-L option

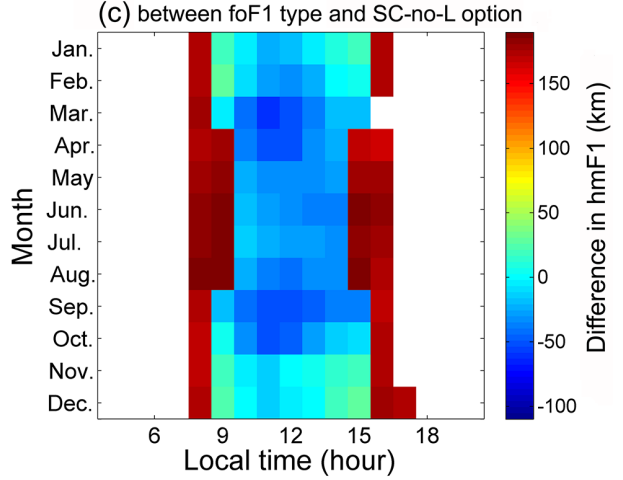

(d) between foF1+ledge type and SC-with-L option

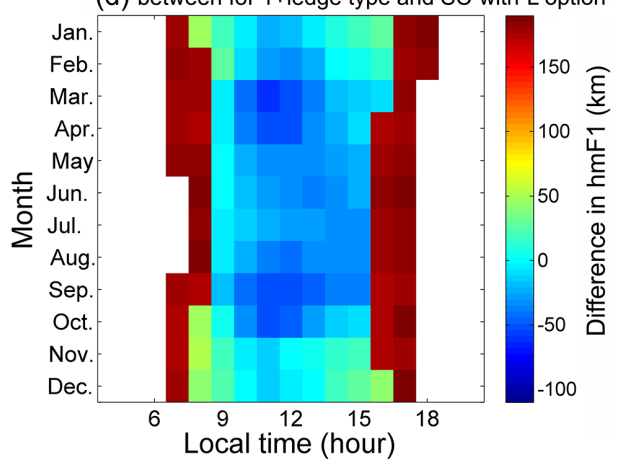

Figure 5. The monthly median $h m \mathrm{~F} 1$ values for (a) SC-no-L and (b) SC-with-L options, modeled by of IRI-2012 with the B0 choice of Bil-2000, during January-December 1996. The differences in $h m F 1$ (c) between $f o F 1$ type and SC-no-L option, and (d) between $f o F 1+l e d g e$ type and SC-with-L option are displayed.

with $\chi$. Conversely, the seasonal $h m \mathrm{~F} 1$ variation shows that $h m \mathrm{~F} 1$ is positively correlated with $\chi$, because $h m \mathrm{~F} 1$ is higher (lower) when $\chi$ is larger (smaller) in the winter (equinoctial) months. These suggest that the relationship between $h m \mathrm{~F} 1$ and $\chi$ can not be used to explain the $h m \mathrm{~F} 1$ variations. Furthermore, these diurnal and seasonal variations would not be caused by the $\boldsymbol{E} \times \boldsymbol{B}$ vertical velocity, because the velocity would not affect the ionosphere below $200 \mathrm{~km}$ (Radicella and Adeniyi, 1999; Lee, 2012). In Fig. 3b, the seasonal variation of $f o \mathrm{~F} 1+$ ledge type is similar to that of $f_{o} \mathrm{~F} 1$ type. However, the diurnal $h m \mathrm{~F} 1$ variation of $f o \mathrm{~F} 1+$ ledge type is partially different to that of $f o \mathrm{~F} 1$ type, when the ledge type is included. $h m \mathrm{~F} 1$ descends from 07:00 to 08:00 LT, and then rises to a maximum height at 12:00 LT. Afterward, $h m \mathrm{~F} 1 \mathrm{de}-$ scends again, and then rises from 16:00 to 17:00 LT. Since the ledge-like profile (ledge type) is located just below the F2 layer, the $h m \mathrm{~F} 1$ values are higher in the early morning and late afternoon.

The monthly median values of $h m \mathrm{~F} 1$, modeled by IRI2012, are presented in Figs. 4a-b, 5a-b, and 6a-b. It is noted that the $h m \mathrm{~F} 1$ variations of only SC-no-L and SC-with-L options are shown in these figures, because the $h m \mathrm{~F} 1$ variation of IRI-95 option is the same as that of SC-no-L option. The $h m \mathrm{~F} 1$ variations for the $\mathrm{B} 0$ choice of Gul-1987 are displayed in Fig. 4a-b. In Fig. 4a (SC-no-L option), the $h m \mathrm{~F} 1$ values are highest and lowest in the winter and summer months, respectively. In the summer and equinoctial months, $h m \mathrm{~F} 1$ starts to rise at 09:00 LT, and has a maximum at 11:00 LT. Afterward, $h m \mathrm{~F} 1$ descends to a minimum at 14:00 LT, and then rises again. For the winter months, $h m \mathrm{~F} 1$ rises gradually during daytime. For the other option (Fig. 4b), the diurnal and seasonal variations of SC-with-L option are similar to those of SC-no-L option. Figure $4 \mathrm{c}-\mathrm{d}$ show the differences in $h m \mathrm{~F} 1$ between observation and IRI-2012 with B0 choice of Gul1987. The apparent differences are found at 08:00-09:00 LT and 15:00-16:00 LT in Fig. 4c, and at 07:00-08:00 LT and 16:00-17:00 LT in Fig. 4d, because the time range of appearance for IRI-2012 is shorter than for observation. The significant negative differences are located between March and September. On the other hand, IRI-2012 underestimates $h m \mathrm{~F} 1$ at 12:00-14:00 LT in November and December.

In Fig. 5a-b, the $h m \mathrm{~F} 1$ variations are predicted by the IRI2012 with B0 choice of Bil-2000. It is found in Fig. 5a that $h m \mathrm{~F} 1$ has a diurnal variation. $h m \mathrm{~F} 1$ rises in morning, has a maximum at 12:00 LT, and then descends in afternoon. For the seasonal variation, the $h m \mathrm{~F} 1$ values are higher in the equinoctial and winter months but lower in the summer months. Furthermore, the diurnal and seasonal variations of 
(a) SC-no-L (IRI-95) option

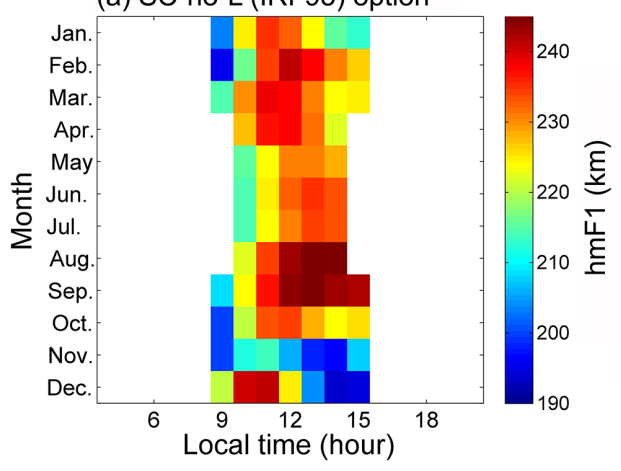

(b) SC-with-L option

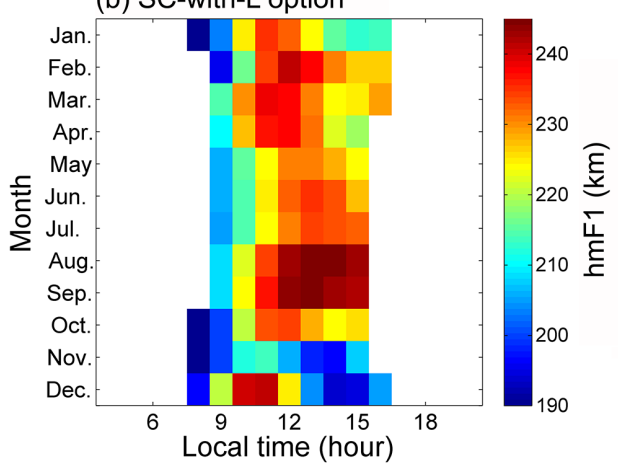

(c) between foF1 type and SC-no-L option

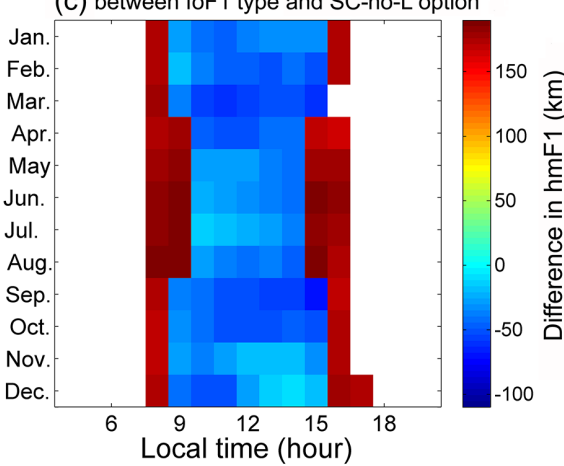

(d) between foF1+ledge type and SC-with-L option

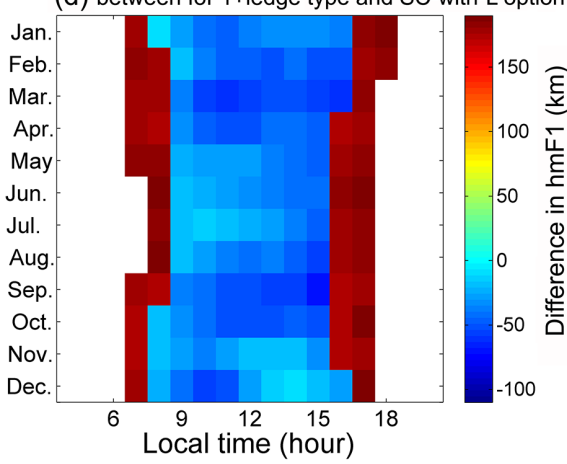

Figure 6. The monthly median $h m \mathrm{~F} 1$ values for (a) SC-no-L and (b) SC-with-L options, modeled by IRI-2012 with the B0 choice of ABT2009, during January-December 1996. The differences in $h m \mathrm{~F} 1$ (c) between $f o F 1$ type and SC-no-L option, and (d) between $f o F 1+l e d g e$ type and SC-with-L option are displayed.

SC-with-L option (Fig. 5b) are similar to those of SC-no-L option (Fig. 5a). For the B0 choice of Bil-2000, the differences in $h m \mathrm{~F} 1$ between observation and IRI-2012 are displayed in Fig. 5c-d. In addition to the apparent positive differences due to the shorter time range, the positive differences exist at 08:00-09:00 and 14:00-16:00 LT in January, February, November, and December. Moreover, it is found that IRI-2012 with B0 choice of Bil-2000 significantly overestimates $h m \mathrm{~F} 1$ during February-October.

Figure $6 \mathrm{a}-\mathrm{b}$ present the $h m \mathrm{~F} 1$ variations of IRI-2012 with B0 choice of ABT-2009. In Fig. 6a, $h m \mathrm{~F} 1$ has a diurnal variation with a daily maximum near noon in January, February, and April-September. In March, and OctoberDecember, $h m \mathrm{~F} 1$ starts to rise at 09:00 LT, and has a maximum at 11:00 LT. Afterward, $h m F 1$ descends to a minimum at 14:00 LT, and then rises again. There is no noticeable seasonal variation in $h m \mathrm{~F} 1$ for this B0 choice. In Fig. $6 \mathrm{c}-\mathrm{d}$, the differences in $h m \mathrm{~F} 1$ between observation and IRI-2012 with B0 choice of ABT-2009 are shown. It is also found that the apparent positive differences due to the shorter time range exist in the early morning and late afternoon. For this B0 choice, IRI-2012 overestimates $h m \mathrm{~F} 1$ in all 12 months of 1996.
In addition to the differences in $h m \mathrm{~F} 1$ described above, the seasonal variation in observed $h m \mathrm{~F} 1$ (Fig. 4) is not similar to those in the IRI-2012 results for all three choices of B0. Overall, IRI-2012 does not give a good prediction of $h m \mathrm{~F} 1$ at Jicamarca during solar minimum. Moreover, among three $\mathrm{B} 0$ choices, the B0 choice of Bil-2000 provides a better representation of $h m \mathrm{~F} 1$. This is not consistent with the result of Bilitza and Rawer (1990), in which they proposed that the B0 choice of Gul-1987 produced a more accurate value of $h \mathrm{mF} 1$.

\subsection{Shape parameter}

In Fig. 7a-b, the monthly median values of D1, obtained from the digisonde observation, are shown. The D1 values have a diurnal variation in both $f o \mathrm{~F} 1$ and $f o \mathrm{~F} 1+$ ledge types. D1 generally starts to increase at 08:00 LT, has a maximum value at 12:00-13:00 LT, and then decreases. Reinisch and Huang (2000) also reported that the diurnal D1 variation at Jicamarca has a systematic behavior going from zero at sunrise, through a maximum at noon, and then to zero again at sunset. Moreover, the D1 values are greater in the summer and winter months, but they are smaller in the equinoctial months. The diurnal and seasonal variations of D1 are qualitatively similar to that of $h m \mathrm{~F} 1$, except in the early morning and late afternoon. 

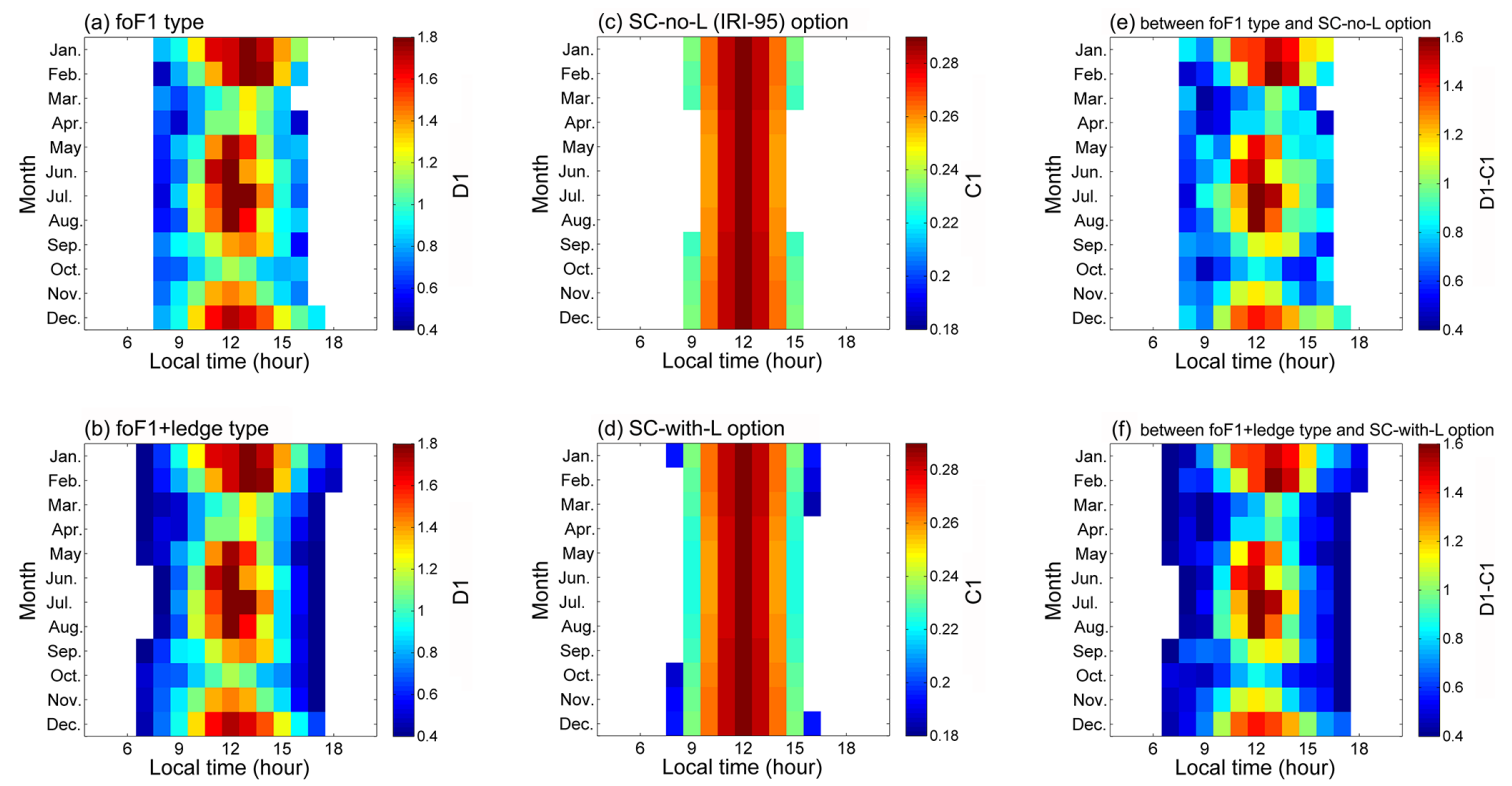

Figure 7. The monthly median $\mathrm{D} 1$ values for the (a) $f \circ \mathrm{F} 1$ and (b) foF1+ledge types of the Jicamarca digisonde, and the monthly median $\mathrm{C} 1$ values for (c) SC-no-L and (d) SC-with-L options of IRI-2012 during January-December 1996. The differences between D1 and C1 (c) for foF1 type and SC-no-L option, and (d) for foF1+ledge type and SC-with-L option are displayed.

Figure 7c-d present the monthly median $\mathrm{C} 1$ values of IRI2012 during January-December 1996. It is noted that the C1 value is applied to calculate the monthly median value, when the corresponding $N m \mathrm{~F} 1$ is greater than 0 . Because the $\mathrm{C} 1$ variation of IRI-95 option is the same as that of SC-no-L option, the results of only SC-no-L (Fig. 7c) and SC-with-L (Fig. 7d) options are presented. For both options, the diurnal $\mathrm{C} 1$ variation has a daily maximum at 12:00 LT. There is no seasonal variation existing in $\mathrm{C} 1$. These variations of $\mathrm{C} 1$ are expected, because the $\mathrm{C} 1$ values are derived from an Epstein function for a given location and time (Bilitza, 1990).

The differences between $\mathrm{D} 1$ and $\mathrm{C} 1$ are displayed in Fig. $7 \mathrm{e}-\mathrm{f}$. The $\mathrm{C} 1$ values are evidently smaller than the $\mathrm{D} 1$ values in all 12 months of 1996 . The positive differences are greater in the summer and winter months, but they are smaller in the equinoctial months. The difference values greater than 1.5 are found at 12:00 LT in May-August and at 13:00 LT in January-February. And the corresponding ratios of $\mathrm{D} 1$ to $\mathrm{C} 1$ are greater than 6.0 , since the $\mathrm{C} 1$ values are 0.28 0.29 . Moreover, in the early morning and late afternoon, the difference values are about 0.4 , and the corresponding ratio of $\mathrm{D} 1$ to $\mathrm{C} 1$ is about 3 . These results indicate that the $\mathrm{D} 1 \mathrm{val}-$ ues of observation are 3-6 times the C1 values of IRI-2012 at Jicamarca during solar minimum.

\section{Conclusion and summary}

In order to know how well IRI-2012 predicts the characteristics of F1 layer near the geomagnetic equator during solar minimum, the observed F1-layer characteristics of the
Jicamarca digisonde are compared with the modeled results. The period of observed and predicted data is between January and December 1996. It is noted that this period is under the solar minimum between the solar cycle 22 and 23 . The characteristics are the occurrence probability, $N m \mathrm{~F} 1, h m \mathrm{~F} 1$, and D1 (C1) of F1 layer.

For observation, the $f_{o} \mathrm{~F} 1$ type of $\mathrm{F} 1$ layer appears during 08:00-16:00 LT, while the $f o \mathrm{~F} 1+$ ledge type exists during 07:00-17:00 LT. However, the time ranges of appearance are between 09:00 and 15:00 LT for the IRI-95 and SC-no-L options, and between 10:00 and 16:00 LT for the SC-with-L option. There is need to extend the time range of appearance predicted by IRI-2012. During 10:00-14:00 LT, the IRI-95 option predicts the occurrence probability of $f o \mathrm{~F} 1$ type well, but the SC-no-L option underestimates the probability. The SC-with-L option underestimates the occurrence probability of $f o \mathrm{~F} 1+$ ledge type during 08:00-16:00 LT. Furthermore, the seasonal variation in occurrence probability is not found in the observed result, but it is found in the modeled results of the SC-no-L and SC-with-L options.

The diurnal and seasonal variations in $N m \mathrm{~F} 1$ for the $f o \mathrm{~F} 1$ and $f o \mathrm{~F} 1+$ ledge types follow a solar zenith angle variation. $N m \mathrm{~F} 1$ has a diurnal variation with a daily maximum at 12:00 LT. For the seasonal variation, the $N m \mathrm{~F} 1$ values are greater in the summer and equinoctial months but smaller in the winter months. $N m \mathrm{~F} 1$ can be represented by the relation of $N m \mathrm{~F} 1=a \cdot \cos ^{n}(\chi)$. In both the diurnal and seasonal variations, the observed and predicted $N m \mathrm{~F} 1$ values are close to each other. IRI-2012 provides a good prediction of $\mathrm{NmF}$. 
For the $f o \mathrm{~F} 1$ type, $h m \mathrm{~F} 1$ begins to ascend at 08:00 LT, has a maximum height at noon, and then falls. This kind of diurnal variation is qualitatively similar to the diurnal $h m \mathrm{~F} 1$ variations for the B0 choices of Bil-2000 and ABT-2009, except in March and October-December for ABT-2009. However, for all three B0 choices, IRI-2012 generally overestimates the $h m \mathrm{~F} 1$ values. For the $f o \mathrm{~F} 1+$ ledge type, the diurnal $h m \mathrm{~F} 1$ variations of observation are different to those of IRI-2012 for all three B0 choices. For the seasonal variation, the observed $h m \mathrm{~F} 1$ values are highest and lowest in the winter and equinoctial months, respectively. The seasonal variation of observation is not similar to those of the model. Overall, IRI2012 does not predict the $h m \mathrm{~F} 1$ values well.

The diurnal variation of D1 has a daily maximum at noon for the $f o \mathrm{~F} 1$ and $f o \mathrm{~F} 1+$ ledge types. Although this kind of diurnal variation can be found in C1 of IRI-2012, the values of $\mathrm{C} 1$ are obviously smaller than those of $\mathrm{D} 1$. The $\mathrm{D} 1$ values are greater in the summer and winter months, but they are smaller in the equinoctial months. However, there is no seasonal variation in $\mathrm{C} 1$. Moreover, the D1 values are 3-6 times the $\mathrm{C} 1$ values.

Acknowledgements. C.-C. Lee was supported by the grant of National Science Council NSC 102-2111-M-231-001 and NSC 1022119-M-231-001. The author would like to thank University of Massachusetts Lowell for access to DIDBase (http://ulcar.uml.edu/ DIDBase/). The author also thank the NASA's National Space Science Data Center (NSSDC) for providing the IRI-2012 model (http://iri.gsfc.nasa.gov/), and the National Geophysical Data Center (NGDC) (http://www.ngdc.noaa.gov/) for providing data of Ap, sunspot number, and F10.7 solar flux.

Topical Editor H. Kil thanks S. Tulasi Ram and two anonymous referees for their help in evaluating this paper.

\section{References}

Abdu, M. A., Batista, I. S., Reinisch, B. W., and Carrasco, A. J.: Equatorial F-layer heights, evening prereversal electric field, and night E-layer density in the American sector: IRI validation with observation, Adv. Space Res., 34, 1953-1965, 2004.

Adeniyi, J. O.: Equatorial F1 characteristics and the international reference ionosphere model, Radio Sci., 31, 893-897, 1996.

Adeniyi, J. O. and Adimula, I. A.: Comparing the F2 layer model of IRI with observations at Ibadan, Adv. Space Res., 15, 141-144, 1995.

Adeniyi, J. O. and Radicella, S. M.: Electron density and height at F1 region minimum gradient at low solar activity for an equatorial station, Radio Sci., 32, 1867-1874, 1997.

Adeniyi, J. O. and Radicella, S. M.: Diurnal variation of ionospheric profile parameters $\mathrm{B} 0$ and $\mathrm{B} 1$ for an equatorial station at low solar activity, J. Atmos. Solar-Terr. Phys., 60, 381-385, 1998a.

Adeniyi, J. O. and Radicella, S. M.: Variation of bottomside profile parameters $\mathrm{B} 0$ and $\mathrm{B} 1$ at high solar activity for an equatorial station, J. Atmos. Solar-Terr. Phys., 60, 1123-1127, 1998 b.
Adeniyi, J. O., Bilitza, D., Radicella, S. M., and Willoughby, A. A.: Equatorial F2-peak parameters in the IRI model, Adv. Space Res., 31, 507-512, 2003.

Altadill, D., Arrazola, D., Blanch, E., and Buresova, D.: Solar activity variations of ionosonde measurements and modeling results, Adv. Space Res., 42, 610-616, 2008.

Altadill, D., Torta, J. M., and Blanch, E.: Proposal of new models of the bottom-side B0 and B1 parameters for IRI, Adv. Space Res., 43, 1825-1834, 2009.

Batista, I. S. and Abdu, M. A.: Ionospheric variability at Brazilian low and equatorial latitudes: comparison between observations and IRI model, Adv. Space Res., 34, 1894-1900, 2004.

Bilitza, D.: International Reference Ionosphere: Recent development, Radio Sci., 21, 343-346, 1986.

Bilitza, D. (Ed.): International Reference Ionosphere 1990, NSSDC 90-22, Greenbelt, Maryland, 1990.

Bilitza, D.: International Reference Ionosphere 2000, Radio Sci., 36, 261-275, 2001.

Bilitza, D. and Rawer, K.: New options for IRI electron density in the middle ionosphere, Adv. Space Res., 10, 7-16, 1990.

Bilitza, D. and Reinisch, B. W.: International Reference Ionosphere 2007: Improvements and new parameters, Adv. Space Res., 42, 599-609, doi:10.1016/j.asr.2007.07.048, 2008.

Bilitza, D., Radicella, S., Reinisch, B. W., Adeniyi, J., Mosert, M. Zhang, S., and Obrou, O.: New B0 and B1 models for IRI, Adv Space Res., 25, 89-95, 2000.

DuCharme, E. D., Petrie, L. E., and Eyfrig, R.: A method for predicting the F1 layer critical frequency based on the Zurich smoothed sunspot number, Radio Sci., 10, 837-839, 1973.

Gulyaeva, T. L.: Progress in ionospheric informatics based on electron density profile analysis of ionogram, Adv. Space Res., 7, 39-48, 1987.

Huang, X. and Reinisch, B. W.: Vertical electron content from ionograms in real time, Radio Sci., 36, 335-342, 2001.

Lee, C. C.: Examination of the absence of noontime bite-out in equatorial total electron content, J. Geophys. Res., 117, A09303, doi:10.1029/2012JA017909, 2012.

Lee, C. C. and Reinisch, B. W.: Quiet-condition $h m \mathrm{~F} 2, N m \mathrm{~F} 2$, and B0 variations at Jicamarca and comparison with IRI-2001during solar maximum, J. Atmos. Solar-Terr. Phys., 68, 2138-2146, 2006.

Lee, C. C. and Reinisch, B. W.:Variations in equatorial F2-layer parameters and comparison with IRI-2007 during a deep solar minimum, J. Atmos. Solar-Terr. Phys., 74, 217-223, 2012.

Lee, C. C., Reinisch, B. W., Su, S.-Y., and Chen, W. S.: Quiettime variations of F2-layer parameters at Jicamarca and comparison with IRI-2001 during solar minimum, J. Atmos. Solar-Terr. Phys., 78, 184-192, 2008.

Obrou, O. K., Bilitza, D., Adeniyi, J. O., and Radicella, S. M.: Equatorial F2 layer peak height and correlation with vertical ion drift and M(3000)F2, Adv. Space Res., 31, 513-520, 2003.

Piggott, W. R. and Rawer, K.: U.R.S.I. Handbook of Ionogram Interpretation and Reduction, Rep. UAG-23A, World Data Center A for Solar Terr. Phys., Boulder, Colorado, 1972.

Radicella, S. M. and Adeniyi, J. O.: Equaotrial ionospheric electron density below the F2 peak, Radio Sci., 24, 1153-1163, 1999.

Rawer, K., Bilitza, D., and Ramakrishnan, S.: International Reference Ionosphere, International Union of Radio Science (URSI), Brussels, Belgium, 1978. 
Reinisch, B. W.: Modern Ionosondes, in: Modern Radio Science, edited by: Kohl, H., Ruester, R., and Schlegel, K., European Geophysical Society, Katlenburg-Lindau, Germany, 440-458, 1996.

Reinisch, B. W. and Huang, X.: Finding better B0 and B1 parameters for the IRI F2 profile function, Adv. Space Res., 22, 741747, 1998.
Reinisch, B. W. and Huang, X.: Redefining the IRI F1 layer profile, Adv. Space Res., 25, 81-88, 2000.

Rishbeth, H. and Garriott, O. K.: Introduction of ionospheric physics, Academic Press, New York and London, 1969.

Scotto, C., Mosert de Gonzáles, M., Radicella, S. M., and Zolesi, B.: On the prediction of F1 ledge occurrence and critical frequency, Adv. Space Res., 20, 1773-1775, 1997. 